EDITORIAL

\title{
Emergent Alliances
}

\author{
Brynjulf Stige ${ }^{12}$ * \\ 1 The Grieg Academy - Dept of Music, University of Bergen \\ 2 Uni Research Health \\ *Brynjulf.Stige@uib.no
}

Published: 1 March 2017

Several commentators claim that trust is eroding in contemporary societies; many people don't trust politicians, some politicians don't trust journalists, certain journalists don't trust each other, and so on and so on. Together with reciprocity and collaboration, trust is a key component of social capital, and more than one political scientist have argued that such capital has decreased in many countries the past decades. More recently, some social researchers have started to discuss the possibility that capitalism in crisis might lead to prolonged periods of social entropy, to the degree that we might see a "post-social society" (Streeck, 2016).

There is also a fast-growing literature on challenged trust in health care practices, examining threats to interpersonal trust as well as to institutional trust. This probably both reflects worries about current societal developments and an increasing awareness of the importance of trust. Scholars in several disciplines have started to think that this should affect the research agendas of health care professions (Groenewegen, 2011).

The present issue of Voices include a number of articles that address similar issues, constructively, by exploring emergent alliances for change. In the interdisciplinary bouquet of articles that we present this time, the authors discuss several emergent processes of change - in practices, theories, and relationships. Innovative alliances are often part of the picture.

In the first research article in this issue, Hiroko Kimura and Yumi Nishimoto present findings from a study of community music therapy for older adults in Norway and Japan. Conditions of community differ by culture, and music therapists should take this into account, the authors argue. After a critical examination of the literature on individualist and collectivist cultures, the authors describe similarities and differences in a Norwegian choir's and a Japanese choir's descriptions of what singing and choir participation means to them.

In another research article, Shoshana Gottesman, a musician activist and educator, presents the findings of a study on how music could be used to create a dialogical space for youth led conflict transformation. She works with Israeli, Palestinian, and Palestinian-Israeli youth who experience intergroup systemic injustice and prolonged and multifaceted conflicts. Could locations of possibilities be built where one typically would find locations of protracted conflicts?

In two different research articles, three Scandinavian arts therapists - Anna Gerge, Margareta Wärja, and Inge Nygaard Pedersen - explore the use of "poetic inquiry" and arts-based research in the pursuit of new knowledge for professional practice as well as an expanded understanding of human knowledge.

In the last research article of this issue, the Israeli researchers Chava Wiess, Ayelet Dassa, and Avi Gilboa present the results of a survey of Israeli music therapists. Which instruments and techniques do music therapists in Israel use, which populations do 
they work with, and what are their theoretical orientations? The results indicate significant differences between older and younger generations of music therapists in this country. Therapists of the younger generation seem to be open to more techniques, proficient with more instruments, and use more music in their work. The authors argue for the relevance of more research on how and why these change have occurred, and on how these developments compare to the situation in other countries.

Younger music therapists use verbal processing less, compared to their older colleagues. This is one of the findings of the Israeli study referred to above. In the position paper that follows, Lori Fogus Gooding from the USA discusses a model for teaching verbal processing skills in music therapy. Communication is central element of music therapy practice, and verbal processing can be an effective tool to facilitate communication with clients, parents, and colleagues, the author argues. She presents a model for training verbal skills that she argues could be of relevance to several approaches to music therapy, regardless of theoretical orientation.

The final piece in this issue is from the genre "From practice" and examines community building through inclusive music-making. The authors - musicologist Jane Gosine and music therapists Deborah Hawksley and Susan LeMessurier Quinn - are all from Canada, and they focus on a project that expands the boundaries of regular music therapy sessions in order to include performances and workshops with community musicians. The practice they describe explores musicking as the creation and performance of relationships.

In various ways, the emergent alliances for change discussed in these articles require and build trust. For a journal such as Voices, which invites interdisciplinary dialogue and discussion about music, health, and social change, this is highly pertinent. The articles are diverse, indeed, and we do not see one research agenda emerging. Instead, we see contours of continued dialogues and discussions on academic, musical, and societal developments.

\section{References}

Groenewegen, P. P. (2011). Trust and the sociology of the professions. European Journal of Public Health, 16(1), 3-6.

Streeck, W. (2016). How will capitalism end? Essays on a failing system. London: Verso. 